\title{
Pneumocystis carinii pneumonia and reticuloses
}

\author{
KEITH R. HUMPHRIES, HENRY NGAN, AND KEITH JAMES \\ From the Royal Marsden Hospital, Sutton, Surrey
}

Three cases of Pneumocystis carinii pneumonia occurring in the course of diseases of the lymphoreticular system are described. One case was diagnosed in life and unsuccessfully treated with pentamidine isethionate. Incidence of the pneumonia is associated with a depressed immune response and may be more frequent than is usually realized in patients with reticuloses who are receiving corticosteroid and cytotoxic drugs.

\begin{abstract}
Pneumocystis carinii pneumonia complicating reticuloses was well described in this country by White, Saxton, and Dawson (1961). The condition occurs in epidemic form among apparently normal children in Central Europe and is frequent in infants with congenital hypogammaglobulinaemia. Successful treatment of the pathogen in children with pentamidine isethionate was described by Marshall, Weston, and Bodian (1964), Rodgers and Haggie (1964), and Robbins, Miller, Arean, and Pearson (1965). An encouraging result with a combination of pyrimethamine, folinic acid, and sulphadiazine in an adult, who acquired the condition following immunosuppressive therapy for renal transplantation, has also been reported (Rifkind, Faris, and Hill, 1966). This paper adds three further cases of Pneumocystis carinii pneumonia which occurred in patients with reticuloses and suggests that now that the lymphomas can be controlled for longer periods the clinical diagnosis of this treatable condition will be made more frequently.
\end{abstract}

\section{CASE REPORTS}

CASE 1 A 22-year-old young woman presented in April 1963 with cervical lymphadenopathy, and biopsy showed Hodgkin's disease. The mediastinum was also involved and she was treated with $15 \mathrm{mg}$. mustine. This was followed by irradiation of the neck and mediastinum. Further radiotherapy, chlorambucil, and prednisone were later given for recrudescence of the lymphadenoma, the prednisone being continued throughout her illness. In March 1966 the patient complained of exertional dyspnoea which gradually progressed until she became breathless at rest. In June 1966 she developed tachycardia and enlarged nodes in the neck, left axilla, and left iliac fossa. Physical

Requests for reprints should be sent to Dr. H. Ngan, Hammersmith Hospital, Ducane Road, London, W.12. examination and a chest radiograph were normal. She was treated with vinblastine, but by August was admitted with severe dyspnoea, cyanosis, pyrexia, and a dry cough. The pulse rate was 120 per minute and respiratory rate 30 per minute. There were no abnormal physical signs in the chest and there was no evidence of cardiac failure. An electrocardiogram was within normal limits, and the arm-to-tongue circulation time was normal. The chest film showed enlarged left hilar and right paratracheal lymph nodes and a diffuse ground-glass cloudiness involving mainly the lower and middle zones on both sides. The E.S.R. was $49 \mathrm{~mm}$./ hour and serum protein $5 \cdot 1$ g. $/ 100 \mathrm{ml}$.

Seven days after admission she collapsed and developed carpo-pedal spasm as a result of respiratory alkalosis. There were now crepitations at the left base. Hydrocortisone and tetracycline were given and oxygen could not be stopped without producing severe cyanosis and restlessness. The oxygen saturation of femoral arterial blood was $78 \%$ while she was receiving oxygen and dropped to $71 \%$ after the oxygen had been stopped for five minutes. Tetracycline was replaced by penicillin, streptomycin, and isoniazid, but crepitations developed all over the chest and a chest radiograph showed increased cloudiness in the lung fields. Bronchial breathing was heard at the left base before she died. At necropsy there were firm, airless, and pinkish-grey lungs. Hodgkin's tissue was present in the spleen and there were several enlarged nodes in the axillae, mediastinum, paraaortic region, and pelvis. Histology of the lungs was typical of Pneumocystis carinii pneumonia.

CASE 2 An 8-year-old boy suddenly developed enlarged lymph nodes on both sides of the neck in December 1965 and a chest radiograph revealed mediastinal widening by enlarged hilar nodes. The haemoglobin was 16.7 g./ $100 \mathrm{ml}$, E.S.R. $6 \mathrm{~mm}$./ hour, W.B.C. 5,400 with a normal differential, and platelets $408,000 /$ c.mm. Serum proteins and electrophoresis were normal. Biopsy of a cervical node showed lymphoblastic lymphosarcoma. Radiotherapy to the 
neck and mediastinum produced rapid regression of the nodes. Towards the end of his course there was a sudden increase in the white blood count, and this was due to the appearance of blast cells; $50 \%$ of the marrow cells were lymphoblasts. He was treated intensively with a combination of vincristine, prednisone, methotrexate, and mercaptopurine simultaneously in an attempt to eradicate the disease. There was a good initial response with remission in the peripheral blood and the marrow. The disease recurred in May and was resistant to chemotherapy. Rubidomycin, a new agent, was tried in July but had no apparent effect. He developed severe, generalized haemorrhagic herpes zoster, became extremely dyspnoeic, and died. Necropsy showed, in addition to the reticulosis and herpes zoster, a mixed pneumonia with both Gram-positive bacteria and Pneumocystis carinii.

CASE 3 A 38-year-old woman presented in December 1964 with generalized lymphadenopathy, and a cervical node biopsy revealed Hodgkin's disease. Examination of the blood showed lymphopenia, and there was dramatic improvement with radiotherapy to the involved areas. Vinblastine and prednisone were given from November 1965 onwards for recrudescence of the lymphadenoma. During the illness she had attacks of herpes simplex, chicken-pox, and warts.

At the beginning of November 1966 she complained of bilateral lower chest pain, a dry cough, and exertional dyspnoea. No abnormality was detected on clinical examination of the chest, but the radiograph showed bilateral fine granular shadowing extending from the hila into the upper and middle zones (Fig. 1).
In view of the experience of the preceding cases an open lung biopsy was performed and showed Pneumocystis carinii pneumonia. The total serum protein concentration was 4.5 g. $/ 100 \mathrm{ml}$. Electrophoresis showed reduced albumin and gammaglobulin. On immunoelectrophoresis, IgG was low at $330 \mathrm{mg} . / 100 \mathrm{ml}$. and IgA and IgM were $15 \%$ and $20 \%$ respectively of reference normal serum.

Treatment was started with a daily intramuscular injection of $225 \mathrm{mg}$. pentamidine isethionate. The injections were given into both buttocks, and after eight injections the patient complained of numbness over a wide area below the injection sites. A day later the lateral aspects of both thighs became red and extremely painful and she developed a high pyrexia. Ampicillin and crystalline penicillin were given for this presumed cellulitis, and an episode of hypotension and oliguria was successfully treated with intravenous hydrocortisone and mannitol. Four days later, herpes zoster-like vesicles appeared on the right thigh along the distribution of the second and third lumbar segments, and shortly afterwards the patient collapsed and died.

At necropsy there was Hodgkin infiltration of the liver, kidney, spleen, and para-aortic lymph nodes. The lungs showed obvious macroscopic involvement with Pneumocystis carinii.

\section{DISCUSSION}

Pneumocystis carinii pneumonia occurs in children with congenital hypogammaglobulinaemia (Burke, Krovetz, and Good, 1961). Although hypogammaglobulinaemia has been recorded in acute lympho-

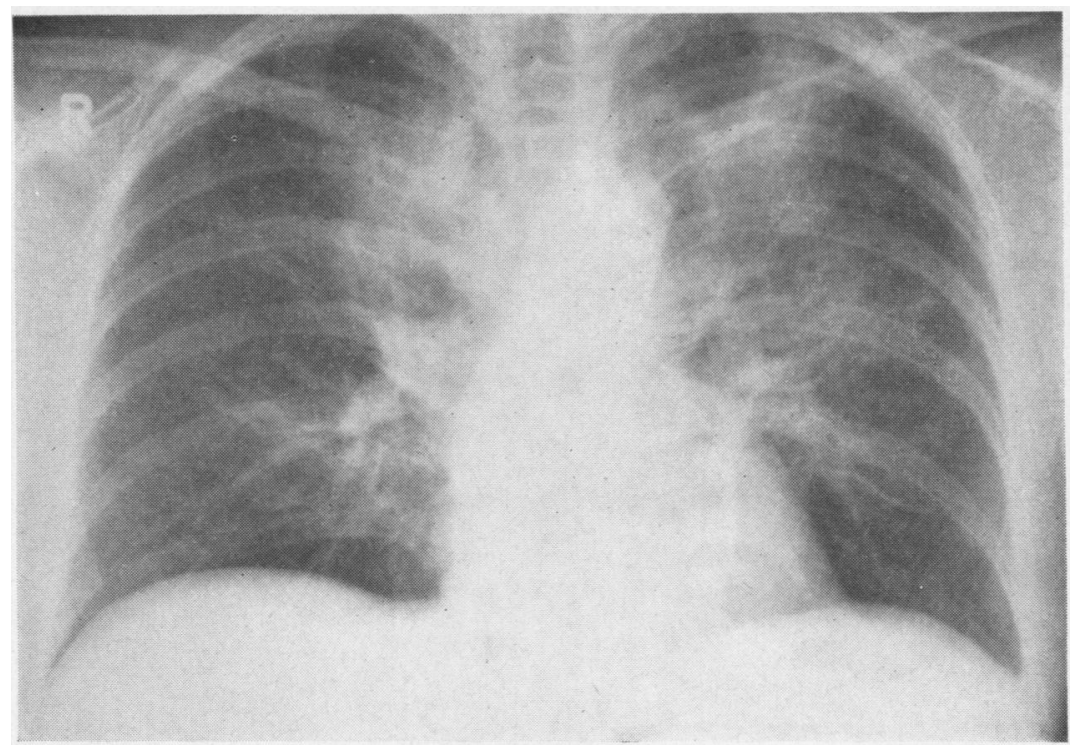

FIG. 1. Case 3. Chest radiograph before treatment. 
blastic leukaemia (Seligmann, Alais, and Bernard, 1959) and Hodgkin's disease (Heremans, 1959), it is not common. Deficient responses to primary immunization sometimes occurs in lymphadenoma (Miller, 1962) and in children treated intensively for acute leukaemia (McKelvey and Carbone, 1965) although the gammaglobulin level remains normal. Ivády, Páldy, Koltay, Tóth, and Kovács (1967) point out that the association of antibodydeficiency syndromes and Pneumocystis carinii infection is not regular and is by no means characteristic. They suggest that cellular defences, especially phagocytic activity, may play a part. The anergy of Hodgkin's disease is well known, and cases 2 and 3 had profound lymphopenia and disseminated herpes zoster. Presumably the humoral factor is more important than the cellular one in resistance to Pneumocystis carinii, but the question remains open. Thorn (1966) has recently emphasized the unfavourable effect of steroids on the host-parasite relationship. $X$-irradiation and many cytotoxic drugs depress the immune response, and antibiotic therapy promotes the emergence of uncommon pathogens by selection.

Extensive radiotherapy in Hodgkin's disease (Kaplan, 1966) and intensive chemotherapy of acute lymphoblastic leukaemia (Zubrod, 1965) have recently been advocated. There is therefore likely to be an increased incidence of infections like torulosis (Misch, 1955), aspergillosis (Gowing and Hamlin, 1960), candidiasis, cytomegalic inclusion disease (Rose, 1966), and Pneumocystis carinii, all formerly considered to be rare.

These cases of Pneumocystis carinii pneumonia demonstrate that, although the pathogen may be merely an opportunist invader, as in case 2 , it can be the probable primary cause of death, as in case 1 , or contribute greatly to morbidity, as in case 3 . Diagnosis of the infection in life is important as it may respond to treatment with pentamidine isethionate (Rodgers and Haggie, 1964 ; Marshall et al., 1964 ; Robbins et al., 1965) or to combined therapy with sulphadiazine, pyrimethamine, and folinic acid, as suggested by Frenkel, Good, and Shultz $(1965,1966)$ and attempted by Rifkind et al. in 1966.

Unfortunately, in the case treated (case 3) death occurred during treatment. From the childhood cases described by Rodgers and Haggie (1964) and Robbins et al. (1965) no improvement in the clinical condition was apparent for one to two weeks or in the radiographic appearance for three

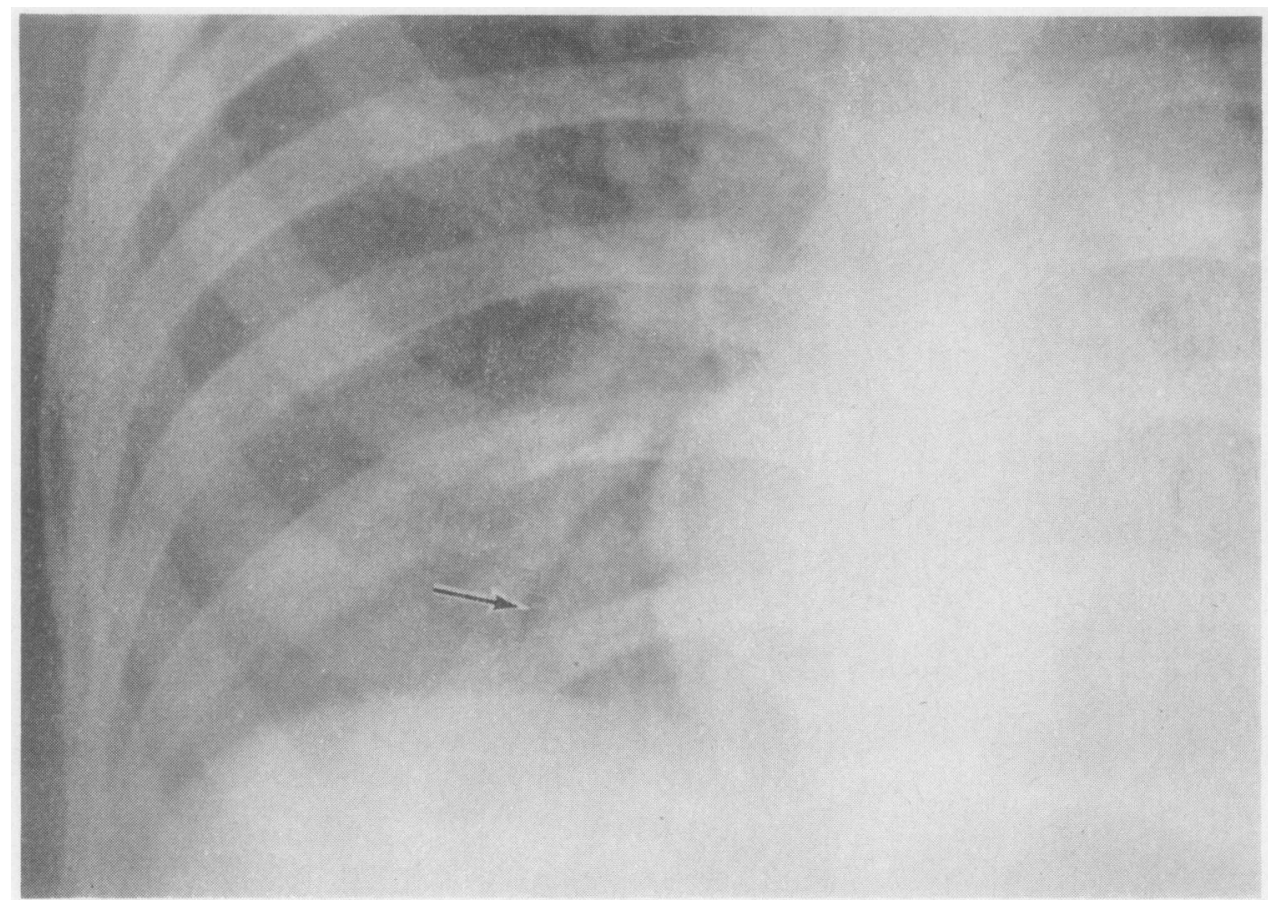

FIG. 2. Case 1. Radiograph showing typical ground-glass appearance of lung fields with translucent bronchi (arrow). 


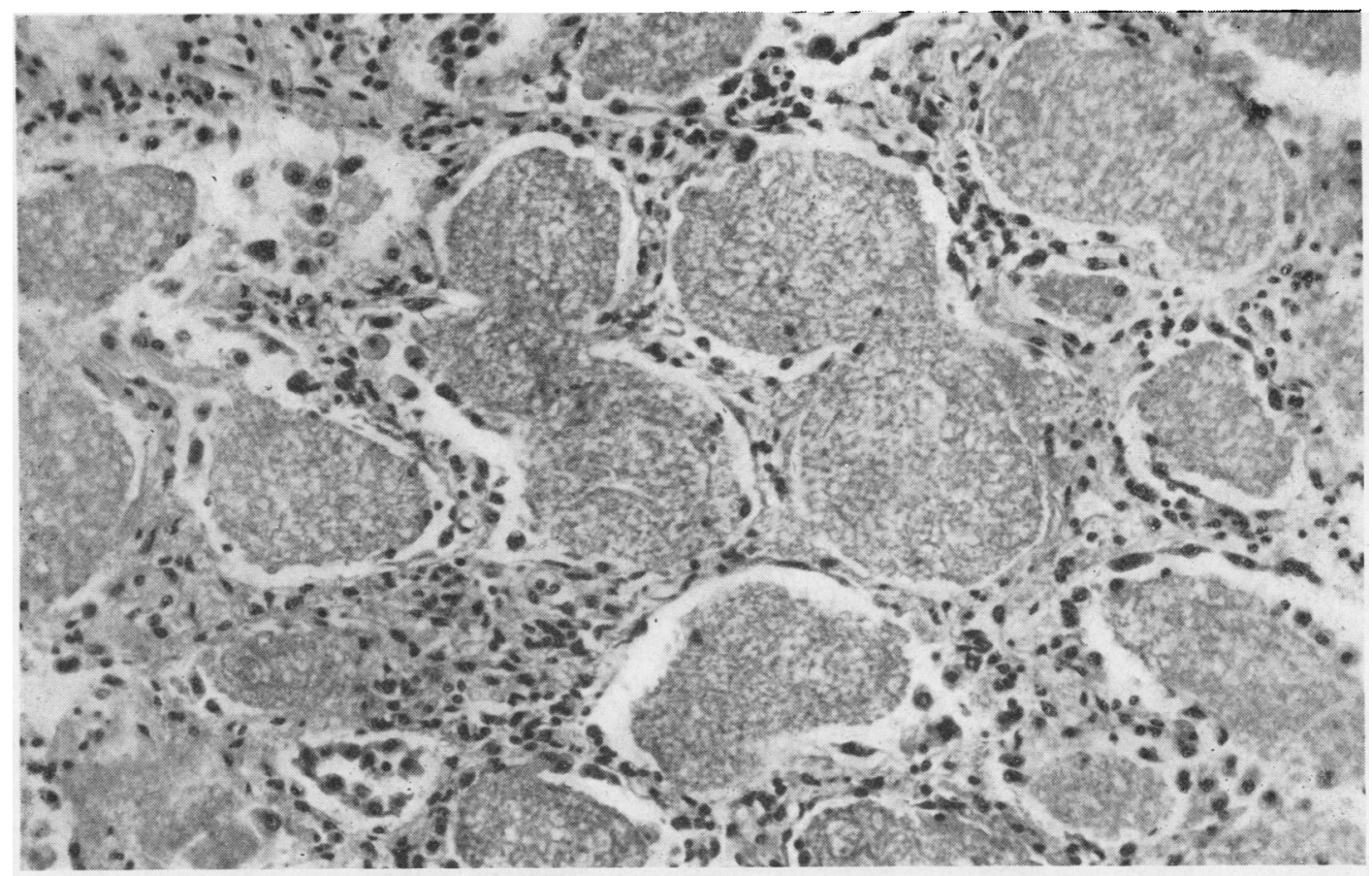

FIG. 3. Case 1. Section of lung showing the typical foamy meshwork filling the alveoli. $H$. and $E . \times 200$.

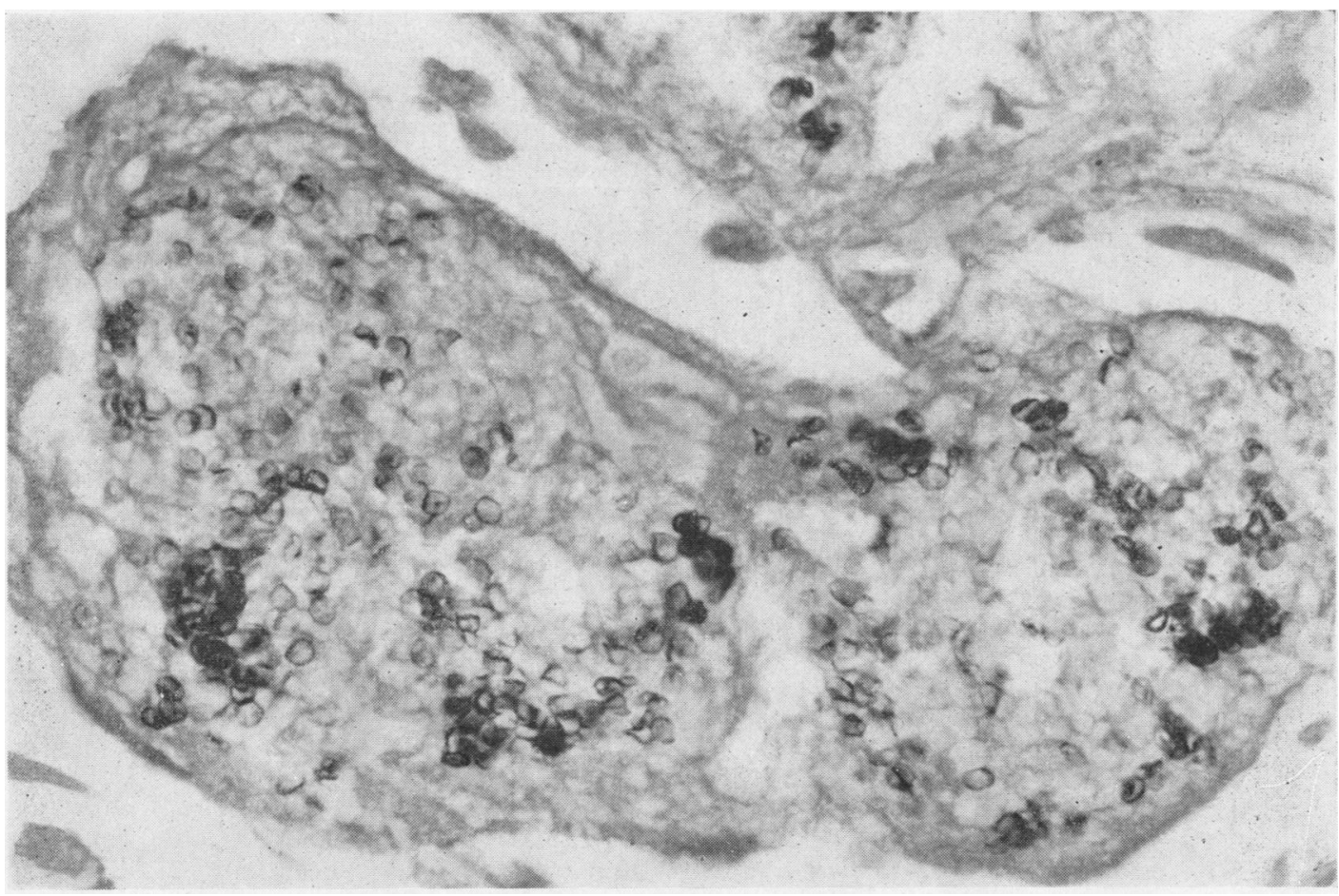

FIG. 4. Case 1. Section of lung stained with Gomori's methenamine silver method to show the presence of cysts in the alveoli. The cysts appear black in the photomicrograph. $\times 675$. 
to four weeks. The persistence of the Pneumocystis carinii pneumonia at necropsy, therefore, did not indicate that pentamidine isethionate was ineffective in the treatment. Indeed, in Pneumocystis carinii pneumonia occurring in normal children the mortality has been reduced from $50 \%$ to $3 \frac{1}{2} \%$ by the use of pentamidine (Ivády, Páldy, and Unger, 1963 ; Ivády et al., 1967).

The clinical features of Pneumocystis carinii pneumonia are low-grade fever, increasing dyspnoea, and eventual cyanosis out of proportion to the physical signs. Cold agglutinins have been demonstrated in three cases (Rifkind et al., 1966). In patients with acute leukaemia the diagnosis is more difficult. Various infections may present with the clinical picture of pulmonary oedema (Bodey, Powell, Hersh, Yeterian, and Freireich, 1966). In any suspected case of Pneumocystis carinii pneumonia chest radiographs may be helpfui, as illustrated by Fig. 2, which shows the typical 'ground-glass cloudiness' with translucent bronchi. Definite diagnosis must depend on the demonstration of the pathogen in a tracheal aspirate. Tracheal mucus is obtained by aspiration through a laryngoscope and stained with methenamine-silver or Giemsa. Ivády et al. (1967) report excellent results with this method in children, but Rifkind et al. (1966) had only one positive smear in four of their adult transplantation patients suffering from the condition. Histological diagnosis is easy: the organism is seen in the alveoli (Figs 3 and 4). Open lung biopsy was resorted to in case 3 as the success of the tracheal aspirate method was not then known to us. The patient's lymphoma was well controlled at the time of biopsy.

Pneumocystis carinii pneumonia is likely to occur in very selected groups of adult patients. Those with reticuloses, those receiving intensive cytotoxic therapy or undergoing organ transplantation, and those receiving corticosteroids at doses greater than $40 \mathrm{mg}$. prednisone daily (Rifkind et al., 1966) are chiefly at risk. Increasing dyspnoea with absence of physical signs should suggest the diagnosis in these situations.

We should like to thank Professor D. W. Smithers, Director of the Department of Radiotherapy, Dr. P. E. Thompson Hancock, Director of Clinical Research, Dr. J. S. Macdonald, Consultant Radiologist, and
Dr. N. F. C. Gowing, Consultant in Morbid Anatomy, for their help and interest. Dr. K. F. W. Hinson, of the Brompton Hospital, kindly provided the histology in case 3, and Mr. A. Ahmed performed the open lung biopsy. We are indebted to Dr. W. C. Marshall, of the Children's Hospital, Great Ormond Street, for his advice and estimation of the immunoglobulins in case 3 .

\section{REFERENCES}

Bodey, G. P., Powell, R. D. J., Jr., Hersh, E. M., Yeterian, A., and Freireich, E. J. (1966). Pulmonary complications of acute leukemia. Cancer, 19, 781.

Burke, B. A., Krovetz, L. J., and Good, R. A. (1961). Occurrence of Pneumocystis carinii pneumonia in children with agammaglobulinemia. Pediatrics, 28, 196.

Frenkel, J. K., Good, J. T., and Shultz, J. (1965). Pathogenesis and chemotherapy of Pneumocystis carinii infection of rats. In Progress in Protozoology. Excerpta med. int. Congr. Ser. No. 91 129. and chemotherapy. Lab. Invest., 15, 1559.

Gowing, N. F. C., and Hamlin, I. M. E. (1960). Tissue reactions to aspergillus in cases of Hodgkin's disease and leukaemia. J. clin. Path., 13, 396.

Heremans, J. F. (1959). Immunochemical studies on protein pathology. The immunoglobulin concept. Clin. chim. Acta, 4, 639.

Ivády, Gy., Páldy, L., Koltay, M., Tóth, G., and Kovács, Z. (1967). Pneumocystis carinii pneumonia (letter). Lancet, 1, 616.

and Unger, G. (1963). Weitere Erfahrungen bei der Behandlung der interstitiellen plasmacellulären Pneumonie mit Pentamidin, Mschr. Kinderheilk., 111, 297.

Kaplan, H. S. (1966). Role of intensive radiotherapy in the management of Hodgkin's disease. Cancer, 19, 356.

Marshall, W. C., Weston, H. J., and Bodian, M. (1964). Pneumocystis carinii pneumonia and congenital hypogammaglobulinaemia. Arch. Dis. Childh., 39, 18.

McKelvey, E., and Carbone, P. P. (1965). Serum immunoglobulin concentrations in acute leukemia during intensive chemotherapy. Cancer, 18, 1292.

Miller, D. G. (1962). Patterns of immunological deficiency in lymphomas and leukemias. Ann. intern. Med., 57, 703.

Misch, K. A. (1955). Torulosis associated with Hodgkin's disease. J. clin. Path., 8, 207.

Rifkind, D., Faris, T. D., and Hill, R. B., Jr. (1966). Pneumocystis carinii pneumonia. Studies on the diagnosis and treatment. Ann. intern. Med., 65, 943.

Robbins, J. B., Miller, R. H., Arean, V. M., and Pearson, H. A. (1965). Successful treatment of Pneumocystis carinii pneumonitis in a patient with congenital hypogammaglobulinemia. New Engl. J. Med., 272, 708 .

Rodgers, T. S., and Haggie, M. H. K. (1964). Pneumocystis carinii pneumonia associated with hypogammaglobulinaemia responding to pentamidine (letter). Lancet, $1,1042$.

Rose, M. S. (1966). Hodgkin's granuloma complicated by generalized cytomegalic inclusion disease and gastrointestinal moniliasis. J. clin. Path., 19, 266.

Seligmann, M., Alais, L., and Bernard, J. (1959). Analyse immunoélectrophorétique du sérum de cent malades atteints de leucoses. Rev. franc. Etudes clin. biol., 4, 901.

Thorn, G. W. (1966). Clinical considerations in the use of corticosteroids. New Engl.J. Med., 274, 775

White, W. F., Saxton, H. M., and Dawson, I. M. P. (1961). Pneumocystis pneumonia. Report of 3 cases in adults and one in a child with a discussion of the radiological appearances and predisposing factors. Brit. med. J., 2, 1327.

Zubrod, C. G. (1965). Combinations of drugs in the treatment of acute leukemias. Proc. roy. Soc. Med., 58, 988. 